\title{
Peningkatan Nilai Tambah Usaha Olahan Keripik Pisang di Desa Tenajar, Kabupaten Indramayu, Jawa Barat
}

\section{(The Added Value Improvement of Banana Chips Business in Tenajar Village, Indramayu District, West Java)}

\author{
Hartoyo $^{{ }^{*}}$, Sutrisno Koswara ${ }^{2}$, Sulassih ${ }^{3}$, Lokita Rizky Megawati ${ }^{1}$ \\ 1Program Studi Bisnis, Sekolah Bisnis, Institut Pertanian Bogor, Kampus IPB Gunug Gede,Jl. Raya Pajajaran, RT.03/RW.06, \\ Babakan, Bogor Tengah, Kota Bogor 16128. \\ 2Departemen Ilmu dan Teknologi Pangan, Fakultas Teknologi Pertanian, Institut Pertanian Bogor, \\ Kampus IPB Darmaga, Bogor 16680. \\ ${ }_{3}^{3}$ Pusat Kajian Hortikultura Tropika Lembaga Penelitian dan Pengabdian kepada Masyarakat, Institut Pertanian Bogor, \\ Kampus IPB Baranangsiang, Jl. Pajajaran Raya, RT.02/RW.05, Tegallega, Bogor Tengah, Kota Bogor 16129. \\ *Penulis Korespondensi: hartoyo@ipb.ac.id \\ Diterima September 2019/Disetujui Oktober 2019
}

\begin{abstract}
ABSTRAK
Tujuan pengabdian kepada masyarakat ini untuk: 1) Meningkatkan pengetahuan dan keterampilan dalam pengolahan keripik pisang melalui pelatihan bagi kelompok masyarakat di lingkungan Pesantren Syubbanul Yaum, Desa Tenajar, dan 2) Menganalisis nilai tambah usaha olahan keripik pisang. Pelaksanaan kegiatan dilakukan selama Juli-September 2019 (3 bulan) dengan beberapa kegiatan yang dimulai dengan persiapan, pelatihan pembuatan keripik pisang, dan pendampingan. Hasil kegiatan pelatihan menunjukkan adanya peningkatan pengetahuan peserta pelatihan dalam hal pemilihan kualitas bahan sebesar $63,16 \%$, inovasi bentuk sebesar $89,47 \%$, inovasi rasa sebesar $26,32 \%$. Keterampilan peserta mengalami peningkatan untuk menerapkan inovasi terkait bentuk dan rasa keripik. Inovasi bentuk antara lain sarang tawon, memanjang, menyerong, membulat, menyerong bergerigi, dan membulat bergerigi, sedangkan inovasi rasa meliputi keju, cokelat, green tea, gula aren, pedas dan, gurih. Kemampuan peserta dalam membuat keripik pisang dengan ketebalan 1-2 mm meningkat sebesar $26,32 \%$ menggunakan berbagai bentuk pisau. Hasil analisis nilai tambah menunjukkan bahwa pengolahan keripik pisang secara ekonomis mampu memberikan nilai tambah mencapai Rp 8.000/kg dengan rasio nilai tambah sebesar 53,30\% dari nilai penjualan. Keuntungan usaha keripik pisang mencapai Rp $5.200 / \mathrm{kg}$ dengan rasio keuntungan sebesar $65 \%$. Pengolahan keripik pisang ini layak dikembangkan untuk dijadikan usaha bagi kelompok masyarakat pengelola pesantren untuk menumbuhkan kemandirian ekonomi pesantren dan masyarakat desa.
\end{abstract}

Kata kunci: industri rumah tangga, inovasi rasa dan bentuk, keripik pisang, nilai tambah

\begin{abstract}
The objectives of this community service activity are to: 1) Increase knowledge and skills in processing banana chips through training for community groups in the Pesantren (Islamic Boarding School) of Syubbanul Yaum, Tenajar Village, and 2) Analyze the added value of banana chips processing. The activities were carried out during July-September 2019 (3 months) with several activities that began with preparation, training on making banana chips, and technical assistances. The results of the training activities showed that there were knowledge improvement of training participants in terms of: selection the quality of material (by 63.16\%), innovation in the form of banana chips (by $89.47 \%$ ), and innovation in the taste of banana chips (by 26.32\%). The skills of participants have been improved to apply innovation in the terms of form and flavor of banana chips. The innovations in the form of chips include; wasp nests, elongated, sloped, rounded, jagged and rounded jagged, while flavored innovations include; cheese, chocolate, green tea, palm sugar, spicy and savory. The ability of participants to make banana chips with a thickness of $1-2 \mathrm{~mm}$ was increased by $26.32 \%$ by using various shapes of knives. The result of value added analysis shows that the processing of banana chips can provide economic added value of IDR $8,000 / \mathrm{kg}$ with a value added ratio of $53.30 \%$ of the sales value. The profit of banana chips business reached IDR 5,200/kg with a profit ratio of $65 \%$. There is, therefore, the processing of banana chips is a suitable business for community groups in managing Pesantren to foster the economic independence of Pesantren and village communities.
\end{abstract}

Keywords: added value, banana chips, home industry, innovation in taste and form 


\section{PENDAHULUAN}

Pisang memiliki kandungan gizi seperti vitamin (provitamin A, B, dan C) dan mineral (kalium, magnesium, fosfor, besi, dan kalsium) yang dibutuhkan untuk tubuh (Ogidi et al. 2017). Pisang di Indonesia dibedakan menjadi pisang meja (banana) dan pisang olahan (plantain) (Ekaputri 2013). Pisang kepok dapat dijadikan sebagai alternatif untuk meningkatkan ketahanan pangan berbasis sumber daya lokal karena merupakan pisang plantain (Simmond 1966) yang memiliki kandungan pati.

Desa Tenajar, Kecamatan Kertasemaya, Kabupaten Indramayu yang terletak pada koordinat 108. 34 BT, -6.50 LS memiliki luas desa 669.600.00 ha dengan tipologi daerah persawahan. Pada musim kemarau sering mengalami kekeringan. Sejumlah 704 orang penduduk mempunyai mata pencaharian sebagai petani dan sejumlah 128 penduduk sebagai buruh tani (Kemendagri 2019), tidak dapat melakukan penanaman padi. Tanaman pisang menjadi alternatif yang dikembangkan, karena tanaman pisang masih dapat bertahan tumbuh pada kondisi kurang air.

Buah pisang memiliki daya simpan yang tidak lama berkisar antara 21-30 hari pada suhu 13$15^{\circ} \mathrm{C}$ (Verheij \& Coronel 1991). Pisang termasuk buah klimaterik karena menunjukkan adanya peningkatan $\mathrm{CO}_{2}$ yang mendadak selama pematangan buah. Kecepatan pemasakan pisang terjadi karena zat tumbuh mendorong pemecahan tepung dan penimbunan gula. Oleh karena itu untuk mengantisipasi kerusakan akibat daya simpan buah, perlu dilakukan upaya diversifikasi produk melalui bentuk olahan pisang seperti keripik. Yayasan Syubbanul Yaum berpotensi untuk mengembangkan produk olahan keripik pisang dengan menambahkan inovasi dalam bentuk dan rasa, sehingga dapat meningkatkan daya saing dan nilai tambah buah pisang.

Keripik pisang dapat dijadikan sebagai usaha bisnis berskala industri rumah tangga, karena dapat memberikan keuntungan dan nilai tambah yang termasuk ke dalam golongan sedang (15-40\%) dengan rasio nilai tambah sebesar 27,04\% (Mubarok et al. 2015). Perubahan bentuk segar menjadi bentuk olahan dapat meningkatkan nilai tambah seperti pada produk kopi laos dan kunyit putih (Nuzuliyah 2018), agroindustri chips jagung (Rahman 2015) dan olahan es krim rumput laut (Fausayana et al.
2019). Tujuan dari kegiatan pengabdian masyarakat adalah 1) Meningkatkan pengetahuan dan keterampilan masyarakat di sekitar pesantren Syubbanul Yaum, Desa Tenajar dalam menghasilkan produk olahan keripik pisang dengan inovasi berbagai bentuk dan rasa, serta kemasan, dan 2) Menganalisis nilai tambah usaha pengolahan keripik pisang. Kegiatan pelatihan dapat menambah peluang usaha bagi masyarakat khususnya orang tua santri dan pengelola pesantren Syubbanul Yaum Desa Tenajar.

\section{METODE PELAKSANAAN KEGIATAN}

\section{Lokasi dan Partisipan}

Program pengabdian masyarakat olahan keripik pisang dilaksanakan pada bulan JuliSeptember 2019. Lokasi kegiatan diselenggarakan di Pesantren Subbhanul Yaum, Desa Tenajar, Kecamatan Kertasemaya, Kabupaten Indramayu. Kegiatan yang dilakukan adalah pelatihan pembuatan olahan keripik pisang dengan inovasi berbagai macam bentuk dan rasa keripik. Peserta kegiatan pelatihan melibatkan orang tua santri dan pengelola pesantren Syubbanul Yaum.

\section{Bahan dan Alat}

Bahan utama yang digunakan dalam kegiatan ini adalah pisang yang sudah tua, kulit berwarna hijau, dan belum mengalami penyemprotan gas karbit atau etephon. Bahan penunjang meliputi plastik kemasan, label kemasan, air, minyak goreng, tepung maizena, perasa keju, green tea, gula aren, cokelat, pedas, dan kaldu ayam. Peralatan yang digunakan adalah kompor mawar, penggorengan, berbagai macam pisau, toples plastik, dan baskom.

\section{Bentuk Kegiatan}

Program pengabdian masyarakat dilakukan dalam beberapa tahap: persiapan, pelatihan, dan pendampingan. Dalam tahap persiapan dilakukan upaya untuk mengidentifikasi calon peserta pelatihan dan inventarisasi potensi tanaman pisang. Pelatihan dilakukan dengan materi mengenai pengetahuan tentang pisang dan berbagai bentuk pengolahan pisang, inovasi dalam pembuatan keripik pisang, yaitu inovasi bentuk, rasa dan kemasan, serta praktik dalam penerapan inovasi. Inovasi bentuk disesuaikan dengan jenis pisau, yaitu sarang tawon, memanjang, bulat, menyerong, membulat bergerigi, dan menyerong bergerigi. Inovasi rasa dilakukan 
dengan mencampur 2 kg keripik pisang yang sudah digoreng dengan $40 \mathrm{~g}$ bumbu tabur aneka rasa (pedas, keju, chicken, green tea, cokelat, dan gula aren), dan $10 \mathrm{~g}$ tepung maizena sangrai. Bahan-bahan tersebut diaduk merata menggunakan stoples bertutup. Kemasan yang digunakan adalah kemasan plastik plip dan diberi label. Setelah pelatihan dilakukan pendampingan untuk mempraktikkan pengetahuan dan keterampilan yang diperoleh dalam pelatihan. Pendampingan dilakukan bekerja sama dengan tim KKN mahasiswa IPB. Kemudian dilakukan analisis nilai tambah dengan menggunakan metode analisis yang dikembangkan
Hayami et al. (1987) dengan kerangka yang disajikan Pada Tabel 1.

\section{HASIL DAN PEMBAHASAN}

\section{Pelatihan Olahan Keripik Pisang melalui Inovasi Variasi Bentuk dan Rasa}

Kegiatan pelatihan mampu meningkatkan pengetahuan mengenai inovasi olahan keripik pisang dalam bentuk dan rasa seperti adanya bentuk keripik yang menjadi ciri khas produk dan berbagai bumbu perasa seperti keju, cokelat, green tea, gula aren, pedas, dan gurih (Gambar 1).

Tabel 1 Analisis nilai tambah pada olahan keripik pisang

\begin{tabular}{|c|c|c|}
\hline Variabel & Sub variabel & Notasi \\
\hline \multirow{6}{*}{ Output, input, dan harga } & Output (kg/produksi) & \multirow{20}{*}{$\begin{array}{l}A \\
B \\
C \\
D=A / B \\
E=C / B \\
F \\
G \\
H \\
I \\
J=D x F \\
K=J-H-I \\
L=(K / I) \times 100 \% \\
M=E x G \\
N=(M / K) \times 100 \% \\
O=K-M \\
P=(0 / K) \times 100 \% \\
Q=J-H \\
R=(M / Q) \times 100 \% \\
S=(I / Q) \times 100 \% \\
T=(O / Q) \times 100 \%\end{array}$} \\
\hline & Input bahan baku (kg/proses produksi) & \\
\hline & Input tenaga kerja (HOK/proses produksi) & \\
\hline & Faktor konversi $(1: 2)$ & \\
\hline & Koefisien tenaga kerja $(3: 2)$ & \\
\hline & Harga output (Rp) & \\
\hline \multirow[t]{10}{*}{ Penerimaan dan keuntungan } & Upah tenaga kerja & \\
\hline & Harga input (Rp/kg) & \\
\hline & Sumbangan input lain $(\mathrm{Rp} / \mathrm{kg})$ & \\
\hline & Nilai ouput & \\
\hline & a. Nilai tambah (Rp/kg) & \\
\hline & b. Rasio nilai tambah (\%) & \\
\hline & a. Pendapatan tenaga kerja (5x7) (Rp/kg) & \\
\hline & b. Bagian tenaga kerja (\%) & \\
\hline & a. Keuntungan $(\mathrm{Rp} / \mathrm{kg})$ & \\
\hline & b. Tingkat keuntungan (\%) & \\
\hline \multirow[t]{4}{*}{ Balas jasa untuk faktor produksi } & Margin (Rp/kg) & \\
\hline & a. Pendapatan tenaga kerja (\%) & \\
\hline & b. Sumbangan input lain (\%) & \\
\hline & c. Keuntungan pengolah (\%) & \\
\hline
\end{tabular}

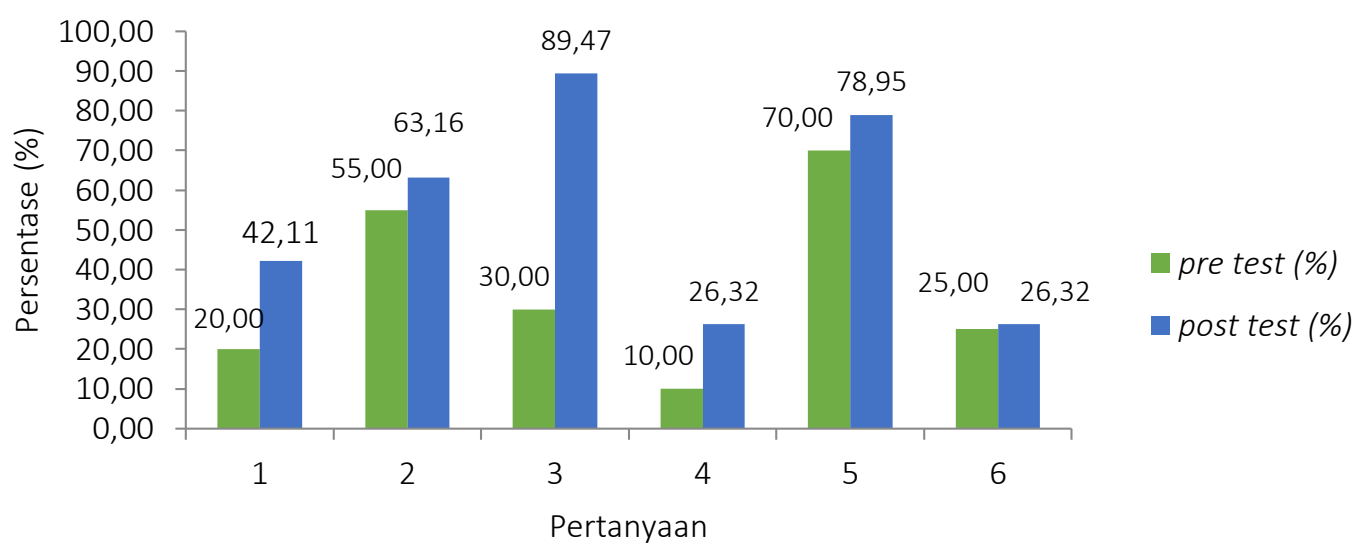

Keterangan: 1 = Kemudahan memperoleh bahan baku pisang, $2=$ Standar kematangan buah pisang, $3=$ Inovasi bentuk keripik, 4 = Inovasi rasa, 5 = Belum ada yang melakukan penjualan keripik pisang, $6=$ Alat yang digunakan masih sederhana.

Gambar 1 Persentase hasil test sebelum dan sesudah pelatihan olahan keripik pisang. 
Olahan keripik pisang pernah dilakukan oleh warga, karena ketersediaan buah pisang cukup mudah, seperti pada Gambar 1 diperoleh hasil post test menyatakan $42 \%$ peserta pelatihan menyatakan kemudahan dalam mendapatkan bahan baku pisang, tetapi usaha tersebut tidak dapat berlangsung lama karena terdapat kendala pengembangan keripik olahan seperti: 1) Peralatan masih tradisional, pesantren memiliki satu mesin pengiris keripik tetapi hasil irisan menjadi tebal, yaitu lebih dari $0,2 \mathrm{~mm}$ dan putaran alat terlalu cepat, sehingga irisan pisang mudah terlempar dan rusak karena benturan mekanis; 2) Jumlah alat yang digunakan terbatas; dan 3) Kesulitan dalam pemasaran, karena hanya dijual di sekitar Desa Tenajar dalam kemasan 100 g, dan mengandalkan pada kegiatan pameran, sehingga belum tercapainya omset pasar.

Peserta pelatihan sebanyak 20 orang wali murid dari pesantren Syubbanul Yaum. Berdasarkan hasil post test (Gambar 1) diperoleh peningkatan pengetahuan peserta dalam menentukan kualitas buah pisang yang baik untuk dijadikan bahan olahan mencapai 63\%, sebelumnya peserta belum banyak mengetahui bagaimana cara pemilihan buah pisang untuk olahan (55\%). Pengetahuan inovasi bentuk keripik menjadi bertambah menjadi $89 \%$, sedangkan sebelum pelatihan mencapai $30 \%$. Peserta mengetahui bentuk keripik memanjang dan membulat, tetapi setelah mengikuti pelatihan, pengetahuan peserta bertambah dengan adanya inovasi bentuk lainnya seperti menyerong, bergerigi menyerong, sarang tawon, dan membulat bergerigi. Inovasi tersebut disebabkan oleh bentuk pisau yang berbeda-beda. Inovasi bentuk menambah daya tarik bagi konsumen sehingga berfungsi meningkatkan nilai tambah. Bentuk sarang tawon merupakan inovasi andalan dalam variasi bentuk keripik.

Keripik pisang umumnya memiliki rasa asin, gurih, dan manis $(10 \%)$, tetapi setelah peserta mengikuti pelatihan terdapat peningkatan pengetahuan (26\%) mengenai inovasi rasa keripik seperti rasa keju, green tea, gula aren, cokelat, pedas, dan kaldu ayam seperti pada Gambar 1. Produksi olahan pisang sudah pernah dilakukan di Desa Tenajar, tetapi tidak berlanjut lama. Hambatannya adalah kesulitan dalam pemasaran karenahanya melakukan penjualan di satu toko dan ditujukan untuk konsumen di sekitar Desa Tenajar. Pelatihan berhasil meningkatkan pengetahuan strategi dalam pemasaran produk melalui media internet dan melalui pameran sebesar 78\%. Pelatihan juga berhasil meningkatkan pengetahuan dalam berbagai macam bentuk pisau sebesar $26 \%$ dengan bentuk dan ketebalan hasil potong yang lebih baik, yaitu menjadi 1-2 mm.

Proses pengolahan diawali dengan memilih buah pisang pisang yang sudah tua, belum masak, kulit berwarna hijau, dan belum mengalami penyemprotan gas karbit atau etephon seperti pada Gambar 2, atau dapat dicirikan dengan adanya satu atau dua buah pisang telah masak dalam satu tandan, yang menandakan kandungan pati sudah mencapai maksimum. Buah pisang dikupas dan diiris dengan ketebalan 1-2 mm dalam berbagai bentuk (Gambar 3), kemudian dicuci sampai getah hilang dan ditiriskan 3-5 menit. Irisan buah pisang digoreng dalam minyak panas dengan suhu $180-200^{\circ} \mathrm{C}$ selama $5-10$ menit (Gambar 4). Jika minyak panas, tidak perlu penambahan perenyah seperti margarin. Penirisan minyak dapat dilakukan dengan menggunakan alat spiner selama 1-2 menit.

Inovasi rasa dilakukan dengan mencampur 2 kg keripik pisang yang sudah digoreng, $40 \mathrm{~g}$ bumbu tabur aneka rasa (balado, keju, chicken, green tea, cokelat, dan gula aren) dan $10 \mathrm{~g}$ tepung maizena sangrai. Bahan-bahan tersebut diaduk merata menggunakan stoples bertutup (Gambar 5). Keripik dengan inovasi rasa dan bentuk

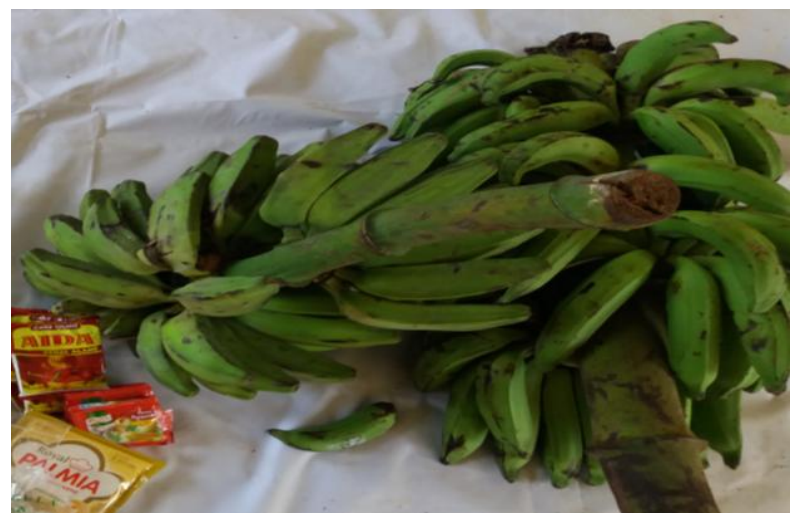

Gambar 2 Pisang yang sudah tua untuk bahan baku pembuatan kripik.
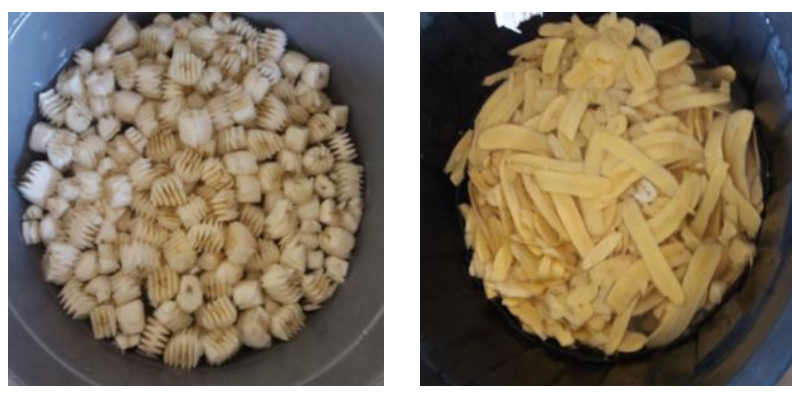

Gambar 3 Buah pisang yang sudah diiris. 
dikemas menggunakan kemasan plastik plip dan diberi label (Gambar 6).

\section{Analisis Nilai Tambah Olahan Keripik Pisang}

Berdasarkan kegiatan produksi yang dilakukan oleh kelompok usaha yang didampingi oleh mahasiswa KKN, setiap proses produksi digunakan bahan baku pisang sebanyak $10 \mathrm{~kg}$ dengan harga sebesar Rp 4.000/kg. Keripik

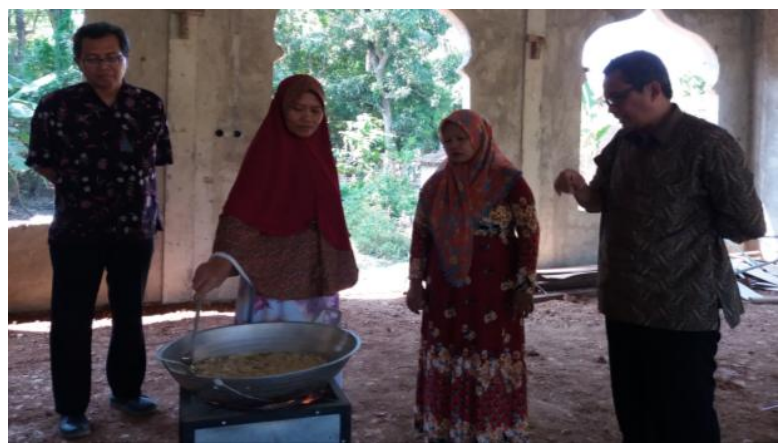

Gambar 4 Proses penggorengan keripik.

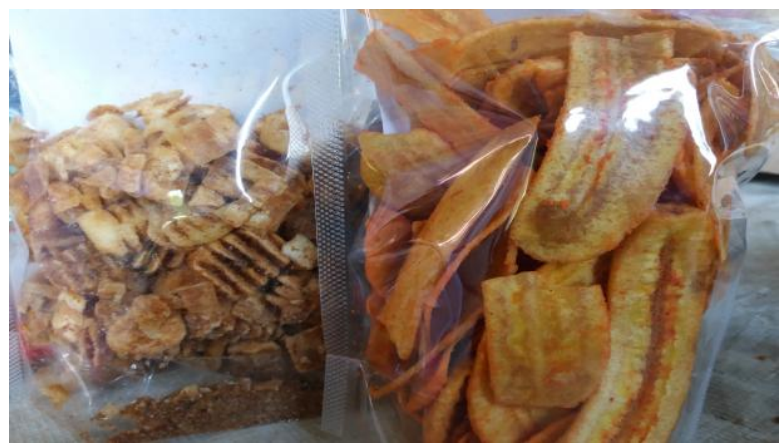

pisang yang dihasilkan sebanyak $3 \mathrm{~kg}$ dengan harga keripik pisang $\mathrm{Rp} 50.000 / \mathrm{kg}$. Untuk menghasilkan keripik pisang itu digunakan bahan input lainnya, yaitu minyak goreng, bumbu, maizena, garam, plastik kemasan, label, dan input lainnya (nilai/harga input disajikan pada Tabel 2). Harga input, seperti terlihat pada Tabel 2 terdiri dari harga pisang (Rp 4.000/kg) dan harga sumbangan input lain (yang telah

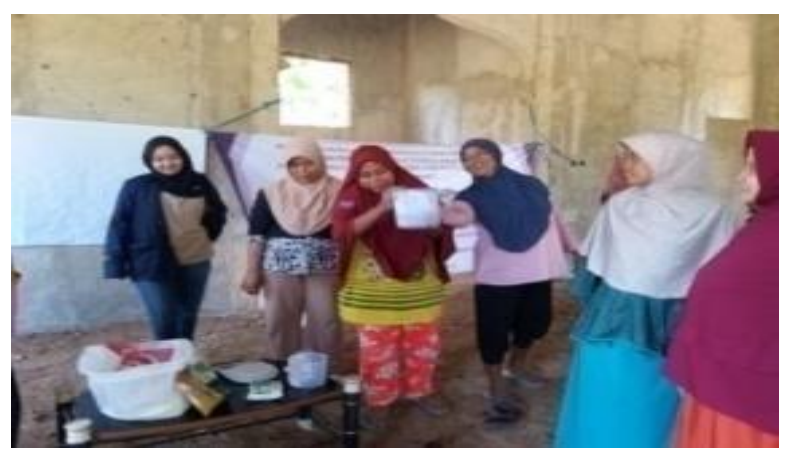

Gambar 5 Proses pengadukan kripik dengan perasa.

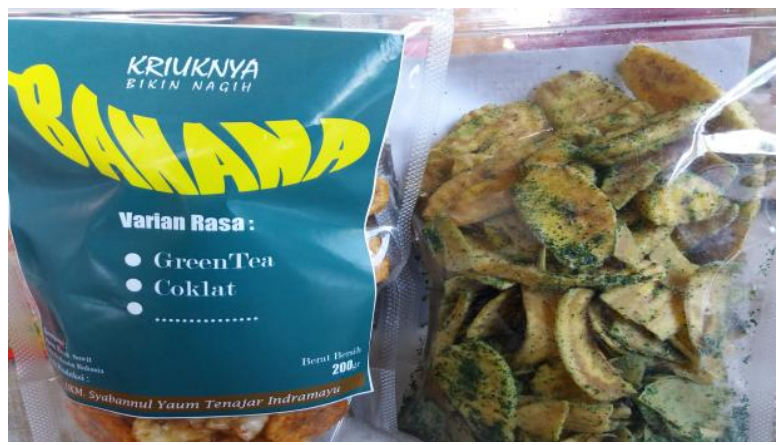

Gambar 6 Keripik yang sudah dikemas.

Tabel 2 Analisis nilai tambah olahan keripik pisang

\begin{tabular}{llr}
\hline \multicolumn{1}{c}{ Variabel } & \multicolumn{1}{c}{ Sub variabel } & Nilai tambah produk \\
\hline Output, input, dan harga & Output (kg) & 3,00 \\
& Input bahan baku (kg/hari) & 10,00 \\
& Input tenaga kerja (H/hari) & 2,00 \\
& Faktor konversi & 0,30 \\
& Koefisien tenaga kerja & 0,20 \\
& Harga output (Rp) & $50.000,00$ \\
& Upah tenaga kerja (JKO) & $14.000,00$ \\
\hline Penerimaan dan keuntungan & Harga input (Rp/kg) & $4.000,00$ \\
& Sumbangan input lain (Rp/kg) & $3.000,00$ \\
& Nilai ouput (Rp) & $15.000,00$ \\
\cline { 2 - 3 } & a. Nilai tambah (Rp/kg) & $8.000,00$ \\
& b. Rasio nilai tambah (\%) & 53,30 \\
\cline { 2 - 3 } & a. Imbalan tenaga kerja (Rp/kg) & $2.800,00$ \\
& b. Bagian tenaga kerja (\%) & 35,00 \\
\cline { 2 - 3 } & a. Keuntungan (Rp/kg) & $5.200,00$ \\
& b. Tingkat keuntungan (\%) & 65,00 \\
\hline Balas jasa untuk faktor produksi & Marjin & $11.000,00$ \\
& Pendapatan TK (\%) & 25,50 \\
& Sumbangan input lain (\%) & 27,30 \\
\hline
\end{tabular}


dilakukan penghitungan dari berbagai input produksi lain (Rp 3.000/kg).

Faktor konversi diperoleh dari perbandingan antara hasil produksi (output) dengan jumlah bahan baku yang digunakan (input) dalam setiap kali proses produksi dengan nilai rasio $0,3 \%$. Hal ini berarti $10 \mathrm{~kg}$ input pisang dihasilkan sebanyak $3 \mathrm{~kg}$ keripik pisang. Kegiatan untuk menghasilkan produksi keripik pisang sebanyak $3 \mathrm{~kg}$ dapat dilakukan oleh dua orang tenaga kerja dengan koefisien tenaga kerja diperoleh sebesar $0,20 \%$, yang menunjukkan bahwa untuk melakukan proses produksi $10 \mathrm{~kg}$ bahan baku diperlukan waktu selama 2 jam.

Berdasarkan hasil analisis yang disajikan pada Tabel 2 terlihat bahwa nilai tambah yang diperoleh adalah sebesar Rp 8.000/kg. Nilai tambah itu terdiri dari imbalan tenaga kerja sebesar Rp 2.800 (35\%) dan keuntungan sebesar Rp 5.200 (65\%). Hal ini menunjukkan bahwa usaha keripik pisang memberikan keuntungan yang cukup besar dan berpotensi untuk meningkatkan pendapatan masyarakat. Oleh karena itu, perlu ada upaya pendampingan dan pembinaan agar usaha keripik pisang ini dapat dikembangkan.

Penerimaan marjinal merupakan tambahan penghasilan yang diperoleh dari tambahan penjualan sebesar satu satuan (Firdaus \& Wasilah 2012). Marjin pendapatan tenaga kerja mencapai $25,50 \%$, sumbangan input lain sebesar $27,30 \%$. Keuntungan yang lebih dari $50 \%$ dari nilai margin akibat pengolahan, mengindikasikan bahwa penjualan produk olahan lebih menguntungkan daripada penjualan dalam bentuk segar/mentah (Nuzuliyah 2018). Keuntungan bagi pengolah olahan keripik pisang mencapai $47,30 \%$. Inovasi bentuk dan inovasi rasa dapat memberikan nilai tambah tergolong tinggi, yaitu di atas 40\% (Hayami et al. 1987) dan dapat memberikan margin tambahan baik untuk pendapatan tenaga kerja, sumbangan input dan keuntungan bagi pengolah (Mubarok et al. 2015).

\section{SIMPULAN}

Kegiatan pengabdian kepada masyarakat yang berupa pelatihan dan pendampingan kepada kelompok ibu-ibu telah meningkatkan pengetahuan (knowledge) dan keterampilan (skill) para peserta. Peningkatan pengetahuan peserta dalam hal pemilihan bahan baku pisang yang berkualitas, pengetahuan bentuk baru keripik, dan pengetahuan rasa baru keripik. Peserta juga telah mampu mempraktikkan inovasi berbagai bentuk keripik yang berupa sarang tawon, memanjang, menyerong, membulat, menyerong bergerigi, dan membulat bergerigi, serta inovasi berbagai rasa di antaranya rasa keju, cokelat, green tea, gula aren, pedas, dan gurih.

Keahlian peserta meningkat sebesar $26,32 \%$ dalam mengiris ketebalan keripik menjadi 1-2 mm dengan menggunakan berbagai bentuk pisau. Berdasarkan hasil analisis nilai tambah menunjukkan pengolahan pisang menjadi keripik pisang mampu memberikan nilai tambah sebesar Rp 8.000/kg dengan rasio nilai tambah sebesar 53,30\% dari nilai penjualan. Keuntungan keripik pisang mencapai $\mathrm{Rp} 5.200 / \mathrm{kg}$ dengan rasio keuntungan sebesar $65 \%$. Marjin pendapatan tenaga kerja mencapai $25,50 \%$, sumbangan input lain sebesar $27,30 \%$, dan keuntungan bagi pengolah mencapai 47,30\%. Hal ini menunjukkan bahwa pengolahan keripik pisang berpotensi untuk meningkatkan pendapatan masyarakat.

Berdasarkan hasil kegiatan ini disarankan untuk terus membina dan mendampingi kelompok ibu-ibu ini agar terus membangun dan mengembangkan kegiatan usaha produktif. Pendampingan diarahkan agar kelompok itu bisa mendaftarkan merek dan produknya ke Dinas Kesehatan, sehingga diperoleh No PIRT, sehingga bisa memperluas izin edar dan mendorong usaha ini bisa berkembang.

\section{UCAPAN TERIMA KASIH}

Penulis mengucapkan terima kasih kepada Kementerian Ristek dan Dikti Republik Indonesia yang telah mendanai program pengabdian masyarakat dengan nomor kontrak 1677/ IT3.L1/PM/2019 tanggal 19 Maret 2019. Penulis juga mengucapkan terima kasih kepada Lembaga Penelitian dan Pengabdian kepada Masyarakat, Institut Pertanian Bogor yang telah mendukung program pengabdian masyarakat. Ucapan terima kasih disampaikan kepada pimpinan pesantren Syubbanul Yaum, Desa Tenajar, Kecamatan Kertasemaya, Kabupaten Indramayu.

\section{DAFTAR PUSTAKA}

Ekaputri S. 2013. Perbandingan keragaman morfologi pisang Kepok Unti Sayang (Musa 
balbisiana) hasil subkultur 1 sampai 6 . [Skripsi]. Bogor (ID): Institut Pertanian Bogor.

Fausayana I, Rosmawaty, Akhyar. 2019. Peningkatan margin kontribusi dan nilai tambah aneka produk olahan rumput laut di Desa Bungin Permai, Konawe Selatan, Sulawesi Tenggara. Agrokreatif Jurnal Ilmiah Pengabdian kepada Masyarakat. 5(1): 71-76. https://doi.org/10.29244/agrokreatif.5.1.7176

Firdaus A, Wasilah A. 2012. Akuntansi Biaya. Edisi 3. Jakarta (ID): Salemba Empat.

Hayami Y, Kawagoe T, Morooka Y, Siregar M. 1987. Agricultural marketing and processing in upland Java. A perspectivefrom a Sunda village. Bogor (ID): CGPRT Centre.

[Kemendagri] Kementerian Dalam Negeri Republik Indonesia. 2019. Data Pokok Desa/Kelurahan. Direktorat Jenderal Bina Pemerintahan Desa. [Internet]. [Diakses pada: 19 Juli 2019]. Tesedia pada: http://www.prodeskel.binapemdes.kemenda gri.go.id/dpokok.
Mubarok AA, Arsyad A, Miftah H. 2015. Analisis nilai tambah dan margin pemasaran pisang menjadi olahan pisang. Jurnal Pertanian. 6(1): $1-11$.

Nuzuliyah L. 2018. Analisis nilai tambah produk olahan tanaman rimpang. Industria: Jurnal Teknologi dan Manajemen Agroindustri. 7(1): 31-38. https://doi.org/10.21776/ub. industria.2018.007.01.4

Ogidi IA, Wariboko C, Alamene A. 2017. Investigation of some nutritional properties of plantain (musa paradisiaca) cultivars in bayelsa state. European Journal of Food Science and Technology. 5(3): 15-35.

Rahman S. 2015. Analisis nilai tambah agroindustri chips jagung. Jurnal Aplikasi Teknologi Pangan. 4(3): 108-111. https://doi.org/10.17728/jatp.v4i3.136

Simmond NW. 1966. Bananas 2nd ed. London (UK): Longmans.512 pp.

Verheij, Coronel RE. 1991. Buah-Buahan yang dapat dimakan dalam Prosea Sumber Daya Nabati Asia Tenggara 2. Jakarta (ID): Gramedia Pustaka Utama. 